\title{
Reptiles Produce Pheomelanin: Evidence in the Eastern Hermann's Tortoise (Eurotestudo boettgeri)
}

Author(s): Alexandre Roulin , Alia Mafli , and Kazumasa Wakamatsu

Source: Journal of Herpetology, 47(2):258-261. 2013.

Published By: The Society for the Study of Amphibians and Reptiles

DOI: http://dx.doi.org/10.1670/12-028

URL: http://www.bioone.org/doi/full/10.1670/12-028

BioOne (www.bioone.org) is a nonprofit, online aggregation of core research in the biological, ecological, and environmental sciences. BioOne provides a sustainable online platform for over 170 journals and books published by nonprofit societies, associations, museums, institutions, and presses.

Your use of this PDF, the BioOne Web site, and all posted and associated content indicates your acceptance of BioOne's Terms of Use, available at www.bioone.org/page/terms_of_use.

Usage of BioOne content is strictly limited to personal, educational, and non-commercial use. Commercial inquiries or rights and permissions requests should be directed to the individual publisher as copyright holder. 


\title{
Reptiles Produce Pheomelanin: Evidence in the Eastern Hermann's Tortoise (Eurotestudo boettgeri)
}

\author{
Alexandre Roulin, ${ }^{1,2}$ Alia Mafli, ${ }^{1}$ and Kazumasa WaKamatsu ${ }^{3}$ \\ ${ }^{1}$ Department of Ecology and Evolution, University of Lausanne, CH-1015 Lausanne, Switzerland \\ ${ }^{3}$ Department of Chemistry, Fujita Health University School of Health Sciences, Toyoake Aichi 470-1192, Japan
}

\begin{abstract}
Aвstract.-Reptiles, supposedly, do not produce pheomelanin pigments. Because this claim is based on rather weak evidence, we measured the shell pheomelanin content in the Hermann's Tortoise (Eurotestudo boettgeri). In contrast to expectation, we detected a substantial amount of this pigment. Given the recent interest in the adaptive function of melanin-based color traits, our study opens new avenues of research in reptiles.
\end{abstract}

In vertebrates, variation in coloration between species and individuals belonging to the same species is mainly attributable to differential deposition of reddish-brown pheomelanin and to black/grey eumelanin pigments (Majerus, 1998). Knowledge of which pigment is responsible for a given color patch is key to understanding the adaptive function of color variation. In vertebrates, melanin-based coloration is associated with a number of ecologically relevant traits, and sign and magnitude of natural and sexual selection exerted on melanin-based coloration can be species or trait specific (Jawor and Breitwisch, 2003; Roulin, 2004; Meunier et al., 2011). Melanin-based coloration can play a major role in predator-prey interactions with eumelanin- and pheomelanin-based coloration conferring camouflage in different habitats (Hoekstra et al., 2005). The physical and biological properties of melanin could also be pigment specific, because melanin is known to protect the external body surface against abrasion (Bonser, 1995), solar radiation (Clusella Trullas et al., 2007), and pathogens (Mackintosh, 2001). In some species, melanin-based coloration has been shown to signal aspects of quality and is, therefore, used as mate choice criterion (Pryke and Griffith, 2007). Although in most of the investigated animal species darker eumelanic individuals were found to be more aggressive and sexually active than paler conspecifics, the adaptive function of pheomelanin-based coloration is still poorly understood (Ducrest et al., 2008).

The genetics of melanogenesis are very well known (Ito and Wakamatsu, 2011), which stimulated researchers to link phenotype to genotype in wild animals (Mundy et al., 2004; Rosenblum et al., 2004; Hoekstra, 2006). Melanogenesis involves complex machinery. By binding to the melanocortin receptor 1, melanocortins induce the production of eumelanin but block the production of pheomelanin and the opposite with agouti signaling protein (ASIP) (Lin and Fisher, 2007; Le Pape et al., 2009). Interestingly, melanocortins have pleiotropic effects on a large number of physiological and behavioral functions (Ducrest et al., 2008). Thus, eumelanin- and pheomelanin-based coloration may be associated with the same phenotypic traits but in opposite directions (Roulin et al., 2011).

There are few reports regarding melanin determination in vertebrates except for mammals and birds (Prota, 1992; Ito, 1998; Ito and Wakamatsu, 2003, 2006). High levels of pheomelanin are found only in yellow to red hairs of mammals and in reddish feathers of birds. Detectable levels of pheomelanin are also detected in human skin regardless of race, color, and skin type. However, eumelanin is always the major constituent of epidermal

${ }^{2}$ Corresponding Author. E-mail: alexandre.roulin@unil.ch DOI: $10.1670 / 12-028$ melanin. In different species of amphibians and reptiles, it has been demonstrated that the pigmented macrophages of the liver are able to synthesize melanins (Cicero et al., 1982, 1989; Scalia et al., 1988). These authors identified pyrrole-2,3,5-tricarboxylic acid (PTCA) and pyrrole-2,3-dicarboxylic acid (PDCA), degradation products of eumelanin, and classified the liver melanin as indole melanin. Gallone et al. (2007) described, in amphibians (Rana esculenta), that liver melanin is composed of 5,6-dihydroxyindole (DHI)-rich eumelanin showing characteristics very similar to those of the sepia melanin, although it contained little pheomelanin (Table 1). Recently, Wolnicka-Glubisz et al. (2012) used EPR spectra and reported that pheomelanin is present in the dorsal skin of adult frogs (Hymenochirus boettgeri). However, they did not quantify the melanin contents. Adachi et al. (2005) reported that the 4-amino-3-hydroxyphenylalanine (4-AHP) level of Red Seabream (Pagrus major) in skin was found to be below the detection limit of $0.015 \mathrm{ng} / \mathrm{mg}$ dry skin, regardless of the season and sex. On the other hand, the average level of PTCA was $4.7 \mathrm{ng} /$ mg dry weight. They demonstrated that pheomelanin has not been identified in any fish.

In reptiles, coloration is often structural or attributable to carotenoid and pteridine pigments (Olsson et al., 2007). Reptiles are thought to produce only eumelanin but not pheomelanin. Many contemporary studies (e.g., Grether et al., 2004; Rosenblum et al., 2004) cite older publications (e.g., Fujii, 1993; Ito and Wakamatsu, 2003) to suggest that reptiles do not produce pheomelanin although these studies did not provide direct evidence. Given the interest in melanin-based color traits among evolutionary ecologists, it is important to either confirm or reject the hypothesis that reptiles have no pheomelanin. To address this question, we performed a study on the Eastern Hermann's tortoise (Eurotestudo boettgeri). This species is native to the Balkans and Greece and displays a high variation in melaninbased coloration between and within populations, as well as within a clutch (Willemsen and Hailey, 1999; Vetter, 2006). The dark shell pigmentation, probably caused by eumelanin, usually covers less than $50 \%$ of each scute, and the rest, which is yellowish to brownish, may be attributable to pheomelanin (Fig. $1)$.

\section{Materials AND Methods}

Our aim was to demonstrate the presence or absence of pheomelanin pigments in the shell of Hermann's Tortoise. For this observational study, we sampled thin shavings from the surface of black, brown, and yellow parts of the shell of three Hermann's Tortoises (adult male, adult female, and juvenile). These tortoises belonged to one of the authors (A. Mafli; for 
TABLE 1. Contents of melanin markers in liver melanin of amphibian, red seabream, and sepia melanin. PTCA and PDCA are degradation markers by acid $\mathrm{KMnO}_{4}$ axidation and/or alkaline $\mathrm{H}_{2} \mathrm{O}_{2}$ oxidation, respectively. 4-AHP is a degradation marker by $\mathrm{HI}$ hydrolysis.

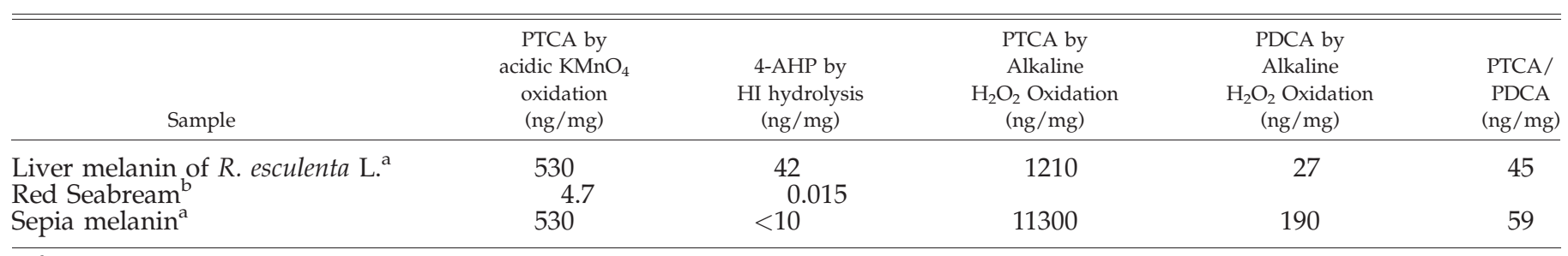

${ }^{\mathrm{a}}$ Gallone et al., 2007.

b Adachi et al., 2005.

further details, also see Mafli et al., 2011) (Fig. 1). Eumelanin content was analyzed by HPLC-chromatography as the permanganate oxidation product PTCA and pheomelanin content was given as the hydriodic acid hydrolysis product 4AHP (Wakamatsu et al., 2002; Ito and Wakamatsu, 2003).

The thin shaving samples, immersed in $1 \mathrm{ml}$ milli-Q water were homogenized with a glass homogenizer. Permanganate oxidation was performed in duplicate at room temperature in $800 \mu \mathrm{l}$ of $1 \mathrm{~mol} / \mathrm{L} \mathrm{H}_{2} \mathrm{SO}_{4} ; 100 \mu \mathrm{l}$ of liver homogenate $(50 \mathrm{mg} / \mathrm{ml})$ was included in the oxidation medium; and $10 \mu \mathrm{l}$ of $3 \% \mathrm{KMnO}_{4}$ was added at regular interval as in the original method (Ito and Fujita, 1985; Ito and Wakamatsu, 1994). $\mathrm{Na}_{2} \mathrm{SO}_{3}(100 \mu \mathrm{l})$ was added, and the reaction mixture was extracted twice using $7 \mathrm{ml}$ of ether. Residue, after evaporating ether extracts, was taken up in $200 \mu \mathrm{l}$ of milli-Q water and centrifuged. An aliquot of $80 \mu \mathrm{l}$ was injected into the HPLC system. Results are averages for duplicate analyses. The HPLC system consisted of a JASCO 880PU liquid chromatograph (JASCO Co., Tokyo, Japan), a Shiseido

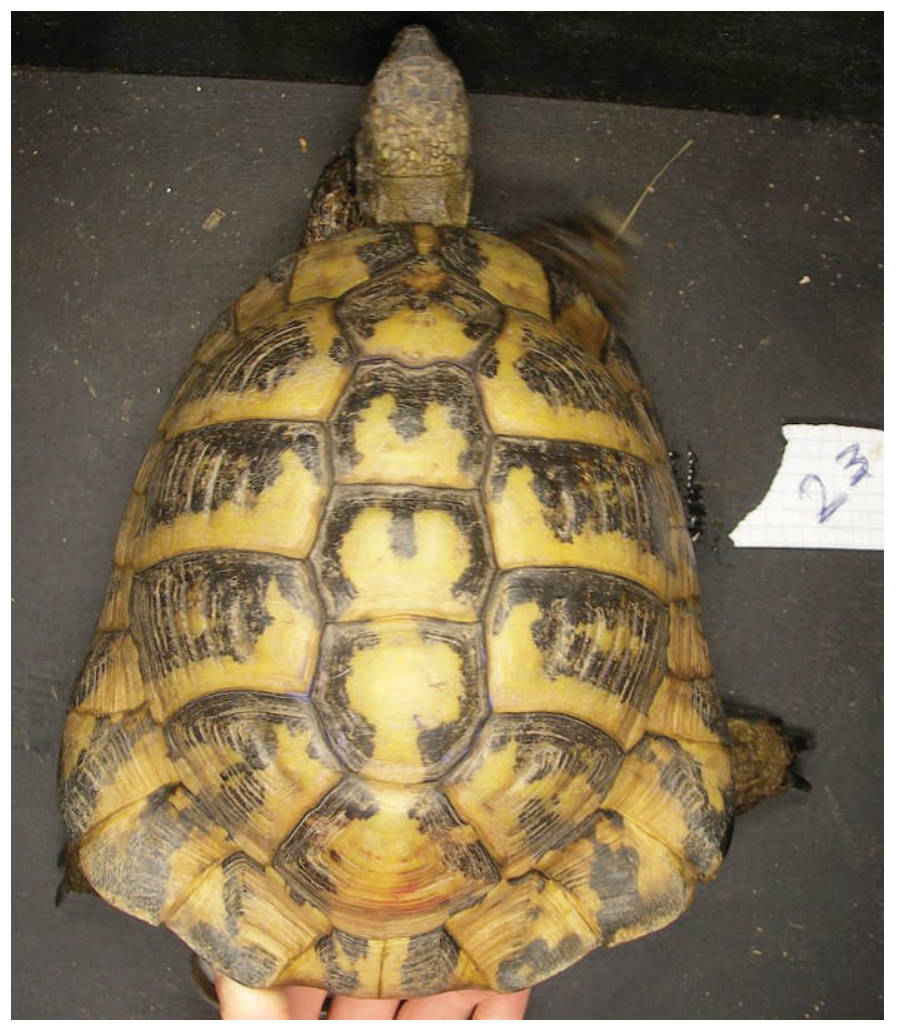

FIG. 1. Eastern Hermann's Tortoise (Eurotestudo boettgeri) displaying yellow with black parts. A distal scute at the center of the animal is partly brown. Photograph by A. Mafli.
C18 column (Capcell Pak Type MG; $4.6 \times 250 \mathrm{~mm} ; 5 \mu \mathrm{m}$ particle size; Shiseido, Tokyo, Japan), and a JASCO UV detector monitored at $269 \mathrm{~nm}$. The mobile phase was $0.1 \mathrm{~mol} / \mathrm{L}$ potassium phosphate buffer ( $\mathrm{pH} 2.1)$ : methanol, $99: 1(\mathrm{v} / \mathrm{v})$. Analyses were performed at $45^{\circ} \mathrm{C}$ at a flow rate of $0.7 \mathrm{ml} / \mathrm{min}$. Permanganate oxidation product, PTCA (pyrrole-2,3-5-tricarboxylic acid) was measured for eumelanin content.

Hydriodic acid reduction was performed by heating a mixture of $100 \mu \mathrm{l}$ of a sample homogenate, $30 \mu \mathrm{l}$ of $30 \% \mathrm{H}_{3} \mathrm{PO}_{2}$, and $500 \mu \mathrm{l}$ of $57 \% \mathrm{HI}$ in a screw-capped tube at $130^{\circ} \mathrm{C}$ for $20 \mathrm{~h}$, after which the mixture was cooled. A $100 \mu \mathrm{l}$ portion of the hydrolysate was transferred to a test tube and evaporated to dryness using a vacuum pump connected to a dry ice-cooled vacuum trap and two filter flasks containing $\mathrm{NaOH}$ pellets. The residue was dissolved in $200 \mu \mathrm{l}$ of $0.1 \mathrm{~mol} / \mathrm{L} \mathrm{HCl} ; 10 \mu \mathrm{l}$ of the solution was analyzed on the HPLC system as described below. The HPLC system consisting of a JASCO 880-PU liquid chromatograph, a JASCO C18 column (JASCO Catechol pak; $4.6 \times 150 \mathrm{~mm} ; 7 \mu \mathrm{m}$ particle size; JASCO, Tokyo, Japan) with AHP buffer : methanol, $(98: 2[\mathrm{v} / \mathrm{v}])$ at $35^{\circ} \mathrm{C}$, with an electrochemical detector (ECD-300, EICOM, Kyoto, Japan) set at $+500 \mathrm{mV}$ versus $\mathrm{Ag} / \mathrm{AgCl}$ electrode, at a flow rate of $0.7 \mathrm{ml} / \mathrm{min}$. The AHP buffer consisted of $0.1 \mathrm{~mol} / \mathrm{L}$ sodium citrate buffer, $\mathrm{pH} 3.0$, containing $1 \mathrm{mmol} / \mathrm{L}$ sodium octanesulfonate and 2\% EDTA.2Na. Finally, HI hydrolysis product, 4-AHP was measured for pheomelanin content (Wakamatsu et al., 2002; Ito and Wakamatsu, 2003).

\section{ResulTs}

The eumelanin/pheomelanin ratio increased along with the change from yellowish to black coloration of the shell (Table 2).

TABLE 2. Content of melanin markers of the yellow, brown, and black parts of the shell in three Hermann's tortoises. Eumelanin content was given by the permanganate oxidation product PTCA and pheomelanin content by the hydriodic acid hydrolysis product 4-AHP.

\begin{tabular}{lccc}
\hline \hline & $\begin{array}{c}\text { Eumelanin } \\
\text { PTCA (ng/mg) }\end{array}$ & $\begin{array}{c}\text { Pheomelanin } \\
\text { 4-AHP (ng/mg) }\end{array}$ & $\begin{array}{c}\text { PTCA/4-AHP } \\
\text { ratio }\end{array}$ \\
\hline $\begin{array}{c}\text { Adult male } \\
\text { Yellow part }\end{array}$ & $<0.14^{\mathrm{a}}$ & 9.72 & $<0.014$ \\
Brown part & 28.8 & 9.46 & 3.04 \\
Black part & 40 & 5.66 & 7.07 \\
Adult female & & 22.2 & $<0.006$ \\
Yellow part & $<0.14^{\mathrm{a}}$ & 8.56 & 7.64 \\
Brown part & 65.4 & 3.87 & 13.59 \\
Black part & 52.6 & 9.45 & $<0.014$ \\
Juvenile & $<0.14^{\mathrm{a}}$ & 11.8 & 8.21 \\
Yellow part & 96.9 & 7.45 & 33.42 \\
Brown part & 249 & & \\
Black part & & & \\
\hline
\end{tabular}

${ }^{a}$ Values below the detection limit of HPLC determination. 
The yellow part of the shell contained mainly pheomelanin pigments. Thus, contrary to the claim that reptiles do not produce pheomelanin, we detected a substantial amount of this pigment in the scutes of Eastern Hermann's Tortoises.

\section{DisCUSSION}

The finding that reptiles do produce pheomelanin pigments is important for several reasons. First, in reptiles yellow/reddish coloration can be attributable to the deposition of carotenoids, pterins, and pheomelanin (Macedonia et al., 2000). Our paper demonstrates that, without analyzing pigments, we cannot discount pheomelanin and assume that the yellow/reddish coloration in reptiles is carotenoid or pterin based. This is important because the carotenoid pigments are derived from the diet, whereas pheomelanin pigments are endogeneously produced.

Second, mammals and birds are already known to produce pheomelanin. Given the close phylogenetic position of birds and reptiles, absence of pheomelanin in reptiles would have implied a secondary loss in the production of this pigment. Our demonstration of the presence of pheomelanin highlights the need for additional data to be collected across a phylogenetically diverse groups of reptiles.

Third, the adaptive function of pheomelanin-based coloration is less well known than of eumelanin-based coloration (Galvan and Solano, 2009; Roulin, 2009). Because reptiles are used frequently by researchers to study the role of natural and sexual selection in the evolution of color traits (e.g., Olsson et al., 2007; Lepetz et al., 2009), we may soon obtain more information on the signaling value of pheomelanin-based coloration in this group of animals. Finally, melanin-based color traits are frequently associated with behavioral traits (Ducrest et al., 2008), but so far most evidence comes from the study of black eumelanic traits. Given that reptiles often vary in both black and yellow/reddish coloration, they appear to be appropriate model organisms to investigate further the relative role of eumelanin and pheomelanin in generating covariation between color and behavioral, morphological, physiological, and life-history traits.

Acknowledgments.-The Swiss National Science Foundation financially supported the study (31003A_120517 to AR) as did the Japan Society for the Promotion of Sciences (JSPS) grant to KW (21500358). We are grateful to S. Dubey, S. Thomas, R. Flint, and two anonymous reviewers who gave useful comments on a previous version of the paper.

\section{Literature Cited}

Adachi, K., K. Kato, K. Wakamatsu, S. Ito, K. Ishimaru, T. Hirata, O. Murata, AND H. KuMAI. 2005. The histological analysis, colorimetric evaluation, and chemical quantification of melanin content in "suntanned" fish. Pigment Cell Research 18:465-468.

BONSER, R. H. C. 1995. Melanin and the abrasion resistance of feathers. Condor 97:590-591.

Cicero, R., S. SCiUto, R. Chillemi, And G. Sichel. 1982. Melanosynthesis in the Kupffer cells of amphibian. Comparative Biochemistry and Physiology 73A:477-479.

Cicero, R., A. Mallardi, I. Maida, A. Gallone, and G. Pintucci. 1989. Melanogenesis in the pigment cells of Rana esculenta L. liver: evidence for tyrosinase-like activity in the melanosome protein fraction. Pigment Cell Research 2:100-108.

Clusella Trullas, S., J. H. van WyK, and J. R. Spotila. 2007. Thermal melanism in ectotherms. Journal of Thermal Biology 32:235-245.
Ducrest, A.-L., L. Keller, and A. Roulin. 2008. Pleiotropy in the melanocortin system, coloration and behavioural syndromes. Trends in Ecology and Evolution 23:502-510.

FujII, R. 1993. Cytophysiology of fish chromatophores. International Review of Cytology 143:191-255.

Gallone, A., A. Sagliano, G. Guida, S. Ito, K. Wakamatsu, V. Capozzi, G. Perna, P. Zanna, and R. Cicero. 2007. The melanogenic system of the liver pigmented macrophages of Rana esculenta L.-tyrosinase activity. Histology and Histopathology 22:1065-1075.

Galvan, I., And F. Solano. 2009. The evolution of eu- and pheomelanic traits may respond to an economy of pigments related to environmental oxidative stress. Pigment Cell Melanoma Research 22:339-342.

Grether, G. F., G. R. Kolluru, and K. Nersissian. 2004. Individual colour patches as multicomponent signals. Biological Reviews 79:583-610.

HoEKSTRA, H. E. 2006. Genetics, development and evolution of adaptive pigmentation in vertebrates. Heredity 97:222-234.

Hoekstra, H. E., J. G. Krenz, and M. W. Nachman. 2005. Local adaptation in the Rock Pocket Mouse (Chaetodipus intermedius): natural selection and phylogenetic history of populations. Heredity 94:217-228.

Iто, S. 1998. Advances in chemical analysis of melanins. In: J. J. Nordlund, R. E. Boissy, V. J. Hearing, R. A. King, and J. P. Ortonne (eds.), The Pigmentary System: Physiology and Pathophysiology, pp. 439-450. Oxford University Press, New York.

Iто, S., AND K. FuлITA. 1985. Microanalysis of eumelanin and pheomelanin in hair and melanomas by chemical degradation and liquid chromatography. Analytical Biochemistry 144:527-536.

Ito, S., AND K. WAKAMATSU. 1994. An improved modification of permanganate oxidation of eumelanin that gives a constant yield of pyrrole-2, 3, 5-tricarboxylic acid. Pigment Cell Research 7:141-144.

. 2003. Quantitative analysis of eumelanin and pheomelanin in humans, mice, and other animals: a comparative review. Pigment Cell Research 16:523-531.

. 2006. Chemistry of melanins. In J. J. Nordlund, R. E. Boissy, V. J. Hearing, R. A. King, W. S. Oetting, and J. P. Ortonne (eds.), The Pigmentary System. Physiology and Pathophysiology. 2nd ed. pp. 282-310. Blackwell Publishing, Oxford.

- 2011. Human hair melanins: what we have learned and have not learned from mouse coat color pigmentation. Pigment Cell Melanoma Research 24:63-74.

JAWOR, J. M., AND R. BREITWISCH. 2003. Melanin ornaments, honesty, and sexual selection. Auk 120:249-265.

Le Pape, T., Passeron, A. Giubellino, J. C. Valencia, R. Wolber, and V. J. HEARING. 2009. Microarray analysis sheds light on the dedifferentiating role of agouti signal protein in murine melanocytes via the Mc1r. Proceedings of the National Academy of Sciences USA 106: 1802-1807.

Lepetz, V., M. Massot, A. S. Chaine, and J. Clobert. 2009. Climate warming and the evolution of morphotypes in a reptile. Global Change Biology 15:454-466.

Lin, J. Y., AND D. E. Fisher. 2007. Melanocyte biology and skin pigmentation. Nature 445:843-850.

Macedonia, J. M., S. James, L. W. Wittle, and D. L. Clark. 2000. Skin pigments and coloration in the Jamaican radiation of Anolis lizards. Journal of Herpetology 34:99-109.

Mackintosh, J. A. 2001. The antimicrobial properties of melanocytes, melanosomes and melanin and the evolution of black skin. Journal of Theoretical Biology 212:101-128.

Mafli, A., K. WAKAMATSU, AND A. Roulin. 2011. Melanin-based coloration predicts aggressiveness and boldness in captive Eastern Hermann's tortoises. Animal Behaviour 81:859-863.

Majerus, M. E. N. 1998. Melanism, Evolution in Action. Oxford University Press, Oxford.

Meunier, J., S. Figueiredo Pinto, R. Burri, and A. Roulin. 2011. Eumelanin-based coloration and fitness parameters in birds: a meta-analysis. Behavioral Ecology and Sociobiology 65:559-567.

Mundy, N. I., N. S. BADCock, T. Hart, T. K. ScRibner, K. JANSSEN, AND N. J. NADEAU. 2004. Conserved genetic basis of a quantitative plumage trait involved in mate choice. Science 303:1870-1873.

Olsson, M., M. Healey, E. Wapstra, T. Schwartz, N. Lebas, and T. Uller. 2007. Mating system variation and morph fluctuations in a polymorphic lizard. Molecular Ecology 16:5307-5315.

Prota, G. 1992. Melanins and Melanogenesis. Academic Press, New York.

PRYKE, S. R., AND S. C. GRIFFITH. 2007. The relative role of male vs. female mate choice in maintaining assortative pairing among discrete colour morphs. Journal of Evolutionary Biology 20:1512-1521. 
Rosenblum, E. B., H. E. Hoekstra, and M. W. Nachman. 2004. Adaptive reptile colour variation and the evolution of the MC1R gene. Evolution 58:1794-1808.

Roulin, A. 2004. The evolution, maintenance and adaptive function of genetic colour polymorphism in birds. Biological Reviews 79:815-848.

. 2009. Melanin-based coloration covaries with ovary size in an age-specific manner in the barn owl. Naturwissenschaften 96:11771184.

Roulin, A., B. Almasi, K. Stier, and L. Jenni. 2011. Eumelanin- and pheomelanin-based colour advertises resistance to oxidative stress in opposite ways. Journal of Evolutionary Biology 24:2241-2247.

Scalia, M., E. Geremia, C. Corsaro, C. Santoro, S. Sciuto, and G. Sichel. 1988. The extracutaneous pigmentary system: evidence for the melanosynthesis in Amphibia and Reptilia liver. Comparative Biochemistry and Physiology 89B:715-717.
VetTer, H. 2006. Tortue d'Hermann, Tortue de Boettger et Tortue d'Herzégovie, Testudo boettgeri, hercegovinensis et hermanni. Editions Chimaria. Allemagne, Frankfurt am Main.

Wakamatsu, K., S. Ito, AND J. L. Rees. 2002. The usefulness of 4-amino-3hydroxyphenylalanine as a specific marker of pheomelanin. Pigment Cell Research 15:225-232.

WillemSEN, R. E., AND A. Hailey. 1999. A latitudinal cline of dark plastral pigmentation in the tortoise Testudo hermanni in Greece. Herpetological Journal 9:125-132.

Wolnicka-Glubisz, A., A. Pecio, D. Podkowa, L. M. KolodziejczyK, and P. M. PlonKA. 2012. Pheomelanin in the skin of Hymenochirus boettgeri (Amphibia: Anura: Pipidae). Experimental Dermatology 21:535-561.

Accepted: 17 September 2012. 